\title{
Crescimento e produtividade de dois cultivares de soja em função de doses de silício
}

\author{
Paulo Henrique Moreira Coelho ${ }^{1}$, Katiane Santiago Silva Benett ${ }^{1}$, Natália Arruda ${ }^{1}$, Cleiton \\ Gredson Sabin Benett ${ }^{1}$, Mariana Vieira Nascimento ${ }^{2}$
}

\author{
${ }^{1}$ Universidade Estadual de Goiás, Campus Ipameri, Ipameri, Goiás, Brasil. E-mail: phmoreiracoelho@ yahoo.com.br, \\ katiane.benett@gmail.com, nathy.a@hotmail.com, cleiton.benett@gmail.com \\ ${ }^{2}$ Universidade Federal de Goiás, Campus Samambaia, Goiânia, Goiás, Brasil. E-mail: nascimento_mariana1@ hotmail.com
}

Recebido: 13/04/2018; Aceito: 29/03/2019.

\section{RESUMO}

A utilização de silício na agricultura tem se tornado cada vez mais comum, pois se evidencia a melhoria de funções fisiológicas e sanitárias das plantas cultivadas. O objetivo do trabalho foi avaliar a influência do silício no crescimento e na produtividade de dois cultivares de soja. O experimento foi conduzido na área experimental da Universidade Estadual de Goiás (UEG), Campus Ipameri. O delineamento utilizado foi em blocos casualizados, no esquema fatorial $2 \times 6$ (cultivares $\mathrm{x}$ doses) com quatro repetições. Os cultivares de soja utilizados foram AS 3730 RR2 IPRO (Intacta) e NA 7490 RR. A aplicação das doses de silício $\left(0,125,250,500,625\right.$ e $750 \mathrm{Kg} \mathrm{ha}^{-1}$ de $\mathrm{Si}$ ) foi realizada no sulco de plantio e a fonte utilizada foi o silicato de cálcio e magnésio em pó. Os dados foram submetidos à análise de variância (teste F) e, em caso de efeito significativo para as doses de silício, de acordo com o teste $\mathrm{F}$, foi realizada a análise de regressão para verificar o efeito das doses nas características avaliadas. Para o efeito isolado dos cultivares, houve diferença significativa para luminosidade do dossel, altura da primeira vagem, número de grãos e peso de mil grãos, porém, para as doses de silício não houve efeito significativo para todas as variáveis. Conclui-se com essa pesquisa que o crescimento e a produtividade dos cultivares de soja AS 3730 IPRO e NA 7490 RR não foram influenciados pelas doses crescentes de silício.

Palavras-chave: Glycine max L., Nutrição mineral, Silicato de cálcio e magnésio.

\section{Growth and productivity of two soybean cultivars as affected by silicon doses}

\begin{abstract}
The use of silicon in agriculture has become increasingly common, as it is evident the improvement of the physiological and sanitary functions of crop plants. The objective of this work was to evaluate the influence of silicon on growth and yield of two soybean cultivars. The experiment was conducted in the experimental area of the State University of Goiás (UEG), in Ipameri, GO, Brazil. The design was completely randomized blocks, in the factorial scheme 2 x 6 (cultivars $x$ doses) with four replicates. The soybean cultivars used were AS 3730 RR2 IPRO (Intacta) and NA $7490 \mathrm{RR}$. The application of the silicon doses $\left(0,125,250,500,625\right.$ and $750 \mathrm{~kg} \mathrm{ha}^{-1}$ of Si) was carried out in the planting and the source used was calcium and magnesium silicate. The data were submitted to analysis of variance ( $\mathrm{F}$ test), in case of a significant effect for the silicon doses, according to the F test, the regression analysis was performed to verify the effect of the doses on the evaluated characteristics. For the isolated effect of the cultivars there was a significant difference for canopy light intensity, height of the first pod, number of grains and weight of one thousand grains, but for silicon doses there was no significant effect for all variables. It is concluded from this research that the growth and productivity of soybean cultivars AS 3730 IPRO and NA 7490 RR were not influenced by increasing doses of silicon.
\end{abstract}

Keywords: Glycine max L., Mineral nutrition, Calcium and magnesium silicate. 


\section{Introdução}

A soja (Glycine $\max (\mathrm{L}$.$) Merrill) pertence à família$ Fabaceae. É a principal cultura agrícola do Brasil e do mundo em termos econômicos e de produção, sendo uma commodity padronizada e uniforme, produzida e negociada por produtores de diversos países. No Brasil, a soja possui a maior área de cultivo em comparação com outras culturas.

Na safra 2018/2019, há uma estimativa de crescimento de $1,9 \%$ em relação à área da safra passada, chegando a 35.821,4 mil de hectares, com uma estimativa de produção de aproximadamente 115,3 milhões de toneladas, com uma produtividade de 3.322 $\mathrm{kg}$ por hectare (Conab, 2019).

Nas últimas décadas houve expressivo aumento da oferta de tecnologias de produção, que permitiram ampliar significativamente a área e a produtividade da oleaginosa (USDA, 2018). A agricultura atual exige o uso adequado de insumos, de modo a atender critérios econômicos e, ao mesmo tempo, conservar o solo, possibilitando manter ou elevar a produtividade das culturas (Philippsen e Simonetti, 2010). Um elemento muito utilizado nos dias atuais e que ainda demanda muitas pesquisas para esclarecer seus benefícios é o silício (Si) (Figueiredo et al., 2010; Reis et al., 2008; Sousa et al., 2010).

O Si é o segundo elemento mais abundante, em peso, na crosta terrestre e componente majoritário de minerais do grupo dos silicatos, mas os principais solos do Cerrado apresentam alto grau de intemperismo, com alto potencial de lixiviação, baixa saturação de bases, baixos teores de Si-trocável e baixas relações (Ki) $\mathrm{SiO}_{2} / \mathrm{Al}_{2} \mathrm{O}_{3}$ e $(\mathrm{Kr})$ Sílica/Sesquióxidos de $\mathrm{Fe}$ e $\mathrm{Al}$, apresentando, portanto, baixa capacidade de fornecimento de Si disponível para as plantas (Ma et al., 2001).

A pesquisa científica tem demonstrado o envolvimento do silício em vários aspectos estruturais, fisiológicos e bioquímicos da vida da planta, com papéis bastante diversos. Além de promover melhorias no metabolismo, ativa genes envolvidos na produção de fenóis e enzimas relacionadas com os mecanismos de defesa da planta (Ávila et al., 2010; Gunes et al., 2007).

Do ponto de vista fitossanitário, o silício ( $\mathrm{Si}$ ) tem aumentado a tolerância de várias espécies de plantas às pragas, doenças, bem como aos diversos tipos de estresses abióticos, tais como: altas temperaturas, falta de água no solo, toxidez de ferro e manganês às raízes, principalmente nas espécies monocotiledôneas (Datnoff et al., 2007).

Reis et al. (2007) verificaram que o Si pode reduzir a transpiração e favorecer a taxa fotossintética das plantas devido à melhoria da arquitetura foliar, e diminuir o auto-sombreamento por proporcionar folhas mais eretas. De acordo com a importância do uso do silício na agricultura e principalmente nos solos do Cerrado, o objetivo dessa pesquisa foi avaliar a interferência da aplicação de doses de silício via solo no crescimento e produtividade de soja em diferentes cultivares.

\section{Material e Métodos}

O experimento foi conduzido na área experimental da Universidade Estadual de Goiás - UEG, Campus Ipameri, localizada no município de Ipameri-GO, com $17^{\circ} 43^{\prime}$ de latitude sul e $48^{\circ} 22^{\prime}$ de longitude oeste e altitude de $764 \mathrm{~m}$.

O clima, segundo a classificação de Köppen, é definindo como Tropical Úmido (AW), constando temperaturas elevadas com chuvas no verão e seca no inverno. Os dados climáticos referentes ao período de condução do trabalho encontram-se na Figura 1.

O solo da área experimental é classificado como Latossolo Vermelho-Amarelo distrófico (Santos et al., 2013). As características químicas do solo foram determinadas antes da instalação do experimento, avaliadas na camada de 0 a $0,20 \mathrm{~m}$, e os resultados da análise química foram 6,4 $\mathrm{mg} \mathrm{dm}^{-3}$ de $\mathrm{P}$ (Melich); $20 \mathrm{~g}$ $\mathrm{dm}^{-3}$ de M.O.; 4,7 de $\mathrm{pH}\left(\mathrm{CaCl}_{2}\right)$; K, Ca, $\mathrm{Mg}$ e $\mathrm{H}+\mathrm{Al}=$ 2,$5 ; 10,0 ; 4,0$ e $35,0 \mathrm{mmol}_{\mathrm{c}} \mathrm{dm}^{-3}$, respectivamente; e a saturação por bases é $32 \%$. A análise granulométrica do solo foi de 475,75 e $450 \mathrm{~g}$ de argila, silte e areia, respectivamente.

O delineamento experimental utilizado foi o de blocos casualizados, em esquema fatorial 2 x 6 (cultivares $\mathrm{x}$ doses) com quatro repetições. Cada parcela experimental foi constituída por cinco metros de comprimento e dois metros de largura, espaçamento entre linhas de $40 \mathrm{~cm}$, com população inicial de 375.000 plantas $\mathrm{ha}^{-1}$, sendo a parcela útil formada pelas três linhas centrais. A semeadura foi realizada em $19 / 11 / 2014$, e os tratamentos aplicados sobre as linhas marcadas pela semeadora logo após a semeadura, no dia 20/11/2014. Foram utilizados dois cultivares de soja certificada, de ciclo precoce e hábito de crescimento indeterminado: AS 3730 RR2 IPRO (Intacta) e NA 7490 RR.

A correção da saturação de bases foi realizada com a aplicação de silicato de cálcio e magnésio, em cada parcela, e as doses foram aplicadas de acordo com cada tratamento. A adubação de base foi realizada simultaneamente à semeadura aplicando-se a quantidade indicada na análise de solo, sendo aplicados $350 \mathrm{~kg} \mathrm{ha}^{-1}$ da fórmula 02-20-18, equivalente à aplicação de $7 \mathrm{~kg}$ ha ${ }^{-1}$ de $\mathrm{N}, 70 \mathrm{~kg} \mathrm{ha}^{-1}$ de $\mathrm{P}_{2} \mathrm{O}_{5}$ e $63 \mathrm{~kg} \mathrm{ha}^{-1}$ de $\mathrm{K}_{2} \mathrm{O}$.

A aplicação das doses de Silício $(0,125,250,500$, 625 e $750 \mathrm{Kg} \mathrm{ha}^{-1}$ de $\mathrm{Si}$ ) foi realizada no sulco de semeadura. A fonte utilizada foi o silicato de cálcio e magnésio em pó, com $25 \%$ de cálcio, $6 \%$ de magnésio e $10,5 \%$ de $\mathrm{Si}$ 


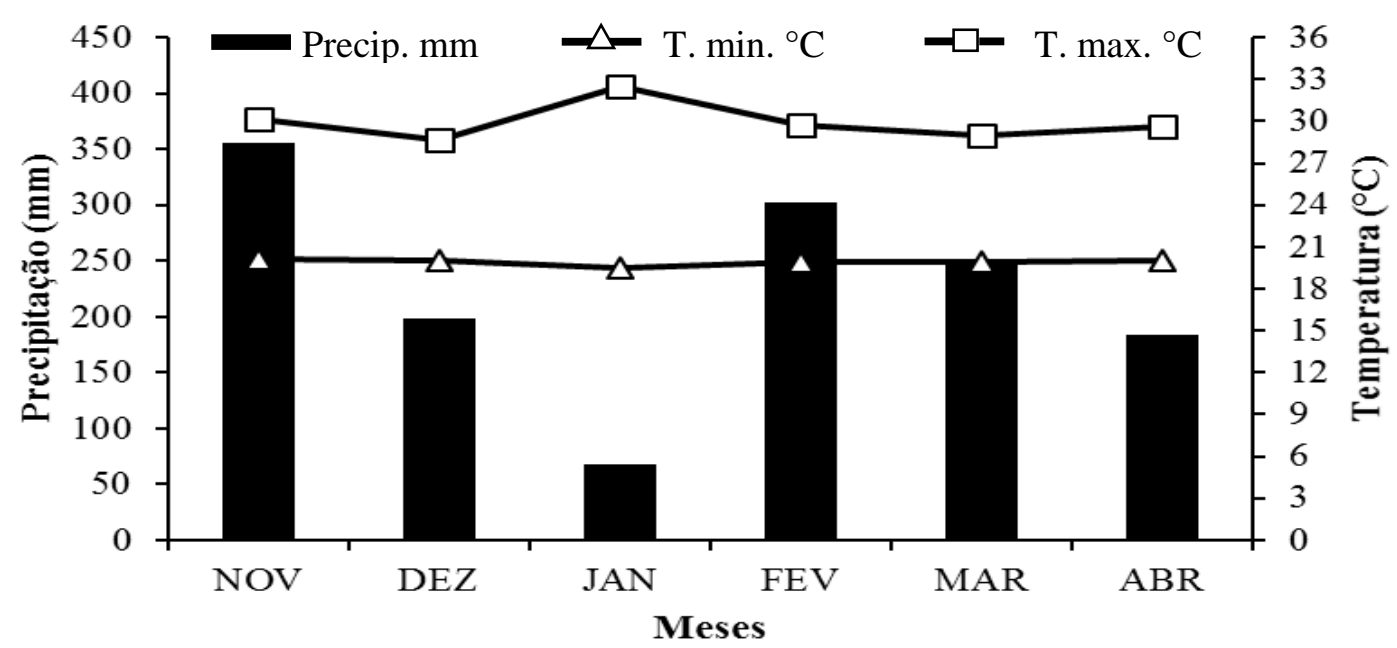

Fonte: INMET, 2016

Figura 1. Valores de Temperatura $\left({ }^{\circ} \mathrm{C}\right)$, e precipitação acumulada $(\mathrm{mm})$ durante o período experimental, Ipameri (GO), 2015.

Devido à composição química do silicato para descartar o efeito de cálcio e de magnésio, foi aplicado calcário nas parcelas do experimento com baixas doses de silício para complementar a quantidade de $\mathrm{Ca}$ e $\mathrm{Mg}$. Dessa maneira, todas as parcelas contêm a mesma quantidade desses nutrientes, entretanto, com diferentes doses de silício.

As avaliações a nível de campo e laboratório foram:

Índice relativo de clorofila: foi realizado em folhas do terço médio das plantas de soja aos 30 dias após emergência das plântulas, utilizando o aparelho clorofiLOG $^{\circledR}, \quad$ o qual determina indiretamente a concentração de clorofila nas folhas pela reflectância do verde no comprimento de onda de aproximadamente $650 \mathrm{~nm}$. Os resultados foram expressos em SPAD.

Luminosidade no dossel: a radiação foi global e as leituras foram realizadas na parte superior, terço médio e base de cada planta, utilizando-se o aparelho DSI 100. Os resultados foram expressos em $\mu \mathrm{mol} \cdot \mathrm{m}^{-2} \cdot \mathrm{s}^{-1}$.

Altura da inserção da primeira vagem: foi realizada a partir da mensuração do colo da planta até a primeira vagem, utilizando régua graduada em centímetros $(\mathrm{cm})$.

Número de vagens e de sementes por planta: foram realizadas as contagens de todas as vagens e sementes por planta.

Produtividade: Foram colhidas todas as plantas da área útil de cada parcela, que corresponde a $6 \mathrm{~m}^{2}$, mensurando-se a massa das sementes, que foi corrigida para o teor de água a $13 \%$ (base úmida) e transformada em toneladas por hectare $\left(\mathrm{t} \mathrm{ha}^{-1}\right)$.

Teor de Silício nas folhas: foram colhidas duas folhas trifolioladas, no terceiro trifólio de cima para baixo, de cinco plantas por parcela e colocadas para secar em estufa com circulação de ar forçada com temperatura de $65^{\circ} \mathrm{C}$, por cerca de 48 horas. Após esse período, o material seco foi moído em moinho tipo Wiley, equipado com peneira de malhas com abertura de $1 \mathrm{~mm}$ e acondicionado em saquinhos de papel para análises. A determinação do teor de silício foliar foi realizada no Laboratório de Nutrição de Plantas da Unesp, Campus de Ilha Solteira, de acordo com a metodologia de Korndörfer et al. (2004).

Os resultados foram submetidos à análise de variância (teste F) e, em caso de efeito significativo para as doses de silício, de acordo com o teste F, realizou-se a análise de regressão para verificar o efeito de doses nas características avaliadas.

\section{Resultados e Discussão}

A análise de variância para todas as características avaliadas está apresentada na Tabela 1. Para o efeito isolado dos cultivares, houve diferença significativa para luminosidade do dossel, altura da primeira vagem, número de grãos e peso de mil grãos, porém, para as doses de silício não houve efeito significativo para todas as variáveis (Tabela 1 ).

A Tabela 2 evidenciou que as médias para o índice relativo de clorofila não diferiram significativamente entre os cultivares. Esses resultados estão de acordo os obtidos por Zago et al. (2010) quando avaliaram a aplicação foliar de silicato de potássio em plantas de soja e não encontraram diferenças no desenvolvimento e nenhuma alteração no processo fotossintético e nos teores de clorofila, porém diferem de Lima et al. (2010), que avaliaram o efeito do silício no manejo de ferrugem da soja e observaram aumento no conteúdo de clorofila b e carotenoides, no teor de lignina das folhas e na redução de doenças. A clorofila, assim como outras moléculas proteicas, é influenciada por vários fatores fisiológicos e nutricionais (Taiz e Zeiger, 2013). 
Para a luminosidade no dossel e altura de inserção da primeira vagem, observou-se diferenças significativas entre os cultivares estudados (Tabela 2). A soja NA 7490 RR apresentou maior luminosidade no dossel, indicando que este cultivar, nestas condições, apresentou melhor constituição da parte aérea, pois a penetração de luz no dossel é uma medida indireta da arquitetura da planta. Reis et al. (2007) afirmam que a melhoria da arquitetura foliar e a diminuição do auto sombreamento ocorrem em consequência de folhas mais eretas. De acordo com Borém et al. (1999), características como morfologia de planta possuem grande variabilidade, por serem muito influenciadas pelo ambiente. Para altura de inserção da primeira vagem, observou-se que o cultivar AS 3730 IPRO apresentou altura de inserção da primeira vagem cerca de $13 \%$ significativamente mais alta do que o cultivar NA 7490 RR (Tabela 2). A altura de inserção de primeira vagem tem importância na diminuição das perdas de colheita mecanizada que ocorrem na plataforma de corte, pois vagens mais baixas podem proporcionar a contaminação dos grãos com solo e palhada. Quanto ao número de vagens, número de grãos, peso de mil grãos e produtividade também não houve interações significativas entre as doses de $\mathrm{Si}$ e os cultivares. Foram verificadas diferenças entre os cultivares apenas para número de grãos por vagem e peso de mil grãos (Tabela 3).

Tabela 1. Análise de variância para índice relativo de clorofila (IRC), luminosidade do dossel (LUM), altura da primeira vagem (ALTV), número de vagens por planta (NV), número de grãos por vagem (NG), teor foliar de silício (TSi), produtividade (PROD) dos cultivares de soja em função de doses silício. Ipameri, 2015.

\begin{tabular}{|c|c|c|c|c|c|c|c|c|c|}
\hline \multirow{2}{*}{ Causa de Variação } & \multicolumn{9}{|c|}{ VALOR-P } \\
\hline & G.L. & IRC & LUM & ALTV & NV & NG & $\mathrm{TSi}$ & P1000 & PROD \\
\hline Cultivar $(\mathrm{C})$ & 1 & $0,68^{\mathrm{ns}}$ & $0,02 *$ & $0,02 *$ & $0,13^{\mathrm{ns}}$ & $0,03 *$ & $0,70^{\mathrm{ns}}$ & $0,01 *$ & $0,17^{\mathrm{ns}}$ \\
\hline Doses (D) & 5 & $0,42^{\mathrm{ns}}$ & $0,52^{\mathrm{ns}}$ & $0,16^{\mathrm{ns}}$ & $0,43^{\mathrm{ns}}$ & $0,21^{\mathrm{ns}}$ & $0,24^{\mathrm{ns}}$ & $0,18^{\mathrm{ns}}$ & $0,06^{\mathrm{ns}}$ \\
\hline $\mathrm{C} \times \mathrm{D}$ & 5 & $0,23^{\mathrm{ns}}$ & $0,73^{\mathrm{ns}}$ & $0,41^{\mathrm{ns}}$ & $0,29^{\mathrm{ns}}$ & $0,60^{\mathrm{ns}}$ & $0,52^{\mathrm{ns}}$ & $0,22^{\mathrm{ns}}$ & $0,13^{\mathrm{ns}}$ \\
\hline $\mathrm{CV} \%$ & & 14,98 & 25,4 & 19,57 & 23,26 & 24,75 & 15,02 & 16,01 & 18,85 \\
\hline
\end{tabular}

*significativo ao nível de $5 \%$ de probabilidade $(\mathrm{p}<0,05)$, ${ }^{\mathrm{ns}}$ não significativo $(\mathrm{p}>0,05)$.

Tabela 2. Índice relativo de clorofila (IRC), luminosidade no dossel (LUM) e altura de inserção da primeira vagem (ALTV) em dois cultivares de soja. Ipameri (GO), 2015.

\begin{tabular}{|c|c|c|c|}
\hline Cultivar & IRC (SPAD) & $\operatorname{LUM}\left(\mu \mathrm{mol} \mathrm{m} \mathrm{m}^{-2} \mathrm{~s}^{-1}\right)$ & $\operatorname{ALTV}(\mathrm{cm})$ \\
\hline $\begin{array}{c}\text { AS } 3730 \text { IPRO } \\
\text { NA } 7490 \text { RR }\end{array}$ & $\begin{array}{l}40,11 \mathrm{a} \\
40,85 \mathrm{a}\end{array}$ & $\begin{array}{l}46.898,35 \mathrm{~b} \\
55.952,27 \mathrm{a}\end{array}$ & $\begin{array}{l}15,26 \mathrm{a} \\
13,31 \mathrm{~b}\end{array}$ \\
\hline \multicolumn{4}{|c|}{ Doses de $\mathrm{Si}\left(\mathrm{Kg} \mathrm{ha}^{-1}\right)$} \\
\hline 0 & 40,95 & $48.733,76$ & 14,33 \\
\hline 125 & 42,02 & $49.280,75$ & 15,87 \\
\hline 250 & 41,43 & $51.849,81$ & 14,71 \\
\hline 500 & 41,04 & $53.206,71$ & 13,88 \\
\hline 625 & 36,12 & $46.323,73$ & 12,04 \\
\hline 750 & 41,36 & $59.157,10$ & 14,92 \\
\hline $\mathrm{CV}(\%)$ & 14,98 & 25,4 & 19,59 \\
\hline
\end{tabular}

* Médias seguidas por letras iguais nas colunas no fator cultivar não diferem entre si pelo teste F. Verificou-se ajuste dos dados para regressão polinomial no fator doses de $\mathrm{Si}$.

Tabela 3. Número de vagens por planta (NV), número de grãos por planta (NG), peso de mil grãos (P 1000), teor de Si (TSi) e produtividade (PROD), em dois cultivares de soja. Ipameri (GO), 2015.

\begin{tabular}{cccccc}
\hline Cultivar & NV & NG & P 1000 (g) & $\begin{array}{c}\text { TSi } \\
\left(\mathrm{g} \mathrm{Kg}^{-1}\right)\end{array}$ & $\begin{array}{c}\text { PROD } \\
\left(\mathrm{Kg} \mathrm{ha}^{-1}\right)\end{array}$ \\
\hline AS 3730 IPRO & $20,18 \mathrm{a}$ & $44,35 \mathrm{~b}$ & $152,17 \mathrm{a}$ & $11,67 \mathrm{a}$ & $3551,66 \mathrm{a}$ \\
NA 7490 RR & $22,36 \mathrm{a}$ & $51,84 \mathrm{a}$ & $128,61 \mathrm{~b}$ & $11,87 \mathrm{a}$ & $3827,70 \mathrm{a}$ \\
\hline \multicolumn{7}{c}{ Doses de Si $\left(\mathrm{Kg} \mathrm{ha}^{-1}\right)$} \\
\hline 0 & 21,49 & $47,80 \mathrm{a}$ & 146,49 & 12,15 & 4070,31 \\
125 & 19,20 & $42,38 \mathrm{a}$ & 148,52 & 11,87 & 3767,19 \\
50 & 24,03 & $56,64 \mathrm{a}$ & 142,59 & 11,82 & 4004,38 \\
500 & 22,35 & 51,58 & 140,20 & 12,15 & 3553,75 \\
750 & 20,76 & 44,86 & 120,65 & 10,31 & 3026,88 \\
\hline CV $(\%)$ & 19,80 & 45,31 & 143,90 & 12,37 & 3715,63 \\
\hline
\end{tabular}

*Médias seguidas por letras iguais nas colunas no fator cultivar não diferem entre si pelo teste $\mathrm{F}$. Verificou-se ajuste dos dados para regressão polinomial no fator doses de $\mathrm{Si}$. 
O presente trabalho não encontrou diferenças significativas para o fator produtividade e número de vagens, porém Pereira Junior et al. (2010) verificaram aumento no número de vagens com o aumento das doses de $\mathrm{Si}$ aplicadas no sulco por ocasião da semeadura. Moreira et al. (2010) observaram incrementos de produtividade no cultivar de soja BRS Favorita RR em condições de campo com aplicação foliar de Si em três estádios fenológicos.

A produtividade dos cultivares ficou em torno de 3551,6 e $3827,70 \mathrm{Kg} \mathrm{ha}^{-1}$ para AS 3730 IPRO e NA 7490 RR, respectivamente. Estes valores estão próximos da produtividade alcançada pelos produtores de soja do país, evidenciando a qualidade e potencial desses cultivares no cerrado. A produtividade semelhante dos dois cultivares pode ser explicada pelo alto nível de melhoramento; sendo assim, neste caso, a aplicação de Si não obteve influência significativa.

Para número e peso de mil de grãos, observou-se uma inversão de valores. Plantas com maior número de grãos apresentaram menor peso de mil grãos e viceversa. O peso médio dos grãos é uma característica determinada geneticamente, sendo esta influenciada por fatores ambientais (Navarro Junior e Costa, 2002).

O cultivar NA 7490 RR tem o ciclo mais longo, podendo chegar a 10 dias de diferença. $\mathrm{O}$ gráfico de temperatura e precipitação (Figura 1) evidenciou que em janeiro houve uma considerável queda de precipitação em comparação aos os meses anteriores e subsequentes.

O cultivar AS 3730 IPRO, com ciclo mais curto, teria passado pelo período de formação dos grãos em um momento de maior disponibilidade de água do que o cultivar NA $7490 \mathrm{RR}$, que tem um ciclo um pouco mais longo, chegando à fase de formação em janeiro, quando a disponibilidade de água foi menor.

$\mathrm{O}$ teor de $\mathrm{Si}$ nas folhas também não apresentou interação entre os cultivares e as diferentes doses de $\mathrm{Si}$ aplicadas (Tabela 3). No caso específico da soja, sendo considerada uma planta intermediária no acúmulo de silício, as respostas à aplicação desse elemento são mais difíceis de serem observadas. Portanto, alterações na metodologia de aplicação de Si à planta, como aumento de dose e forma de aplicação (sulco, cobertura e adubação foliar), poderiam constituir-se em uma nova alternativa de fornecimento dessa substância às plantas (Pereira Júnior et al, 2010).

\section{Conclusões}

$\mathrm{O}$ crescimento e a produtividade dos cultivares de soja AS 3730 IPRO e NA 7490 RR não foram influenciados pelas doses crescentes de silício.

\section{Agradecimentos}

À Universidade Estadual de Goiás (UEG), Campus Ipameri, pelo suporte na condução do projeto, e à FAPEG, pela bolsa de mestrado concedida ao primeiro autor.

\section{Referências Bibliográficas}

Ávila, F.W., Baliza, D.P., Faquin, V., Araujo, J.L., Ramos, S.J., 2000. Interação entre silício e nitrogênio em arroz cultivado sob solução nutritiva. Revista Ciência Agronômica, 41(2), 184-190.

Borém, A., Almeida, L.A., Kiihl, R.A.S., 1999. Hibridização em soja. Hibridização artificial de plantas, 2(1), 443-462.

Conab, Companhia Nacional de Abastecimento, 2019. http://www.conab.gov.br/ (acessado 22 de fevereiro de 2019).

Datnoff, L.E, Rodrigues, F.A., Seebold, K.W., 2007. Silicon and Plant Nutrition. Mineral nutrition and plant disease. Saint Paul, p. 233-246.

Figueiredo, F.C., Botrel, P.P., Teixeira, C.P., Petrazzini, L.L., Locarno, M., Carvalho, J.G., 2010. Pulverização foliar e fertirrigação com silício nos atributos físico-químicos de qualidade e índices de coloração do morango. Ciência e Agrotecnologia, 34(5), 1306-1311.

Gunes, A., Inal, A., Bagci, E.G., Coban, S., 2007. Siliconmediated changes on some physiological and enzymatic parameters symptomatic of oxidative stress in barley grown in sodic-B toxic soil. Journal of Plant Physiology, 164(6), 807811.

Korndörfer, G.H., Pereira, H.S., Nolla, A., 2004. Análise de silício: solo, planta e fertilizante. Instituto de Ciências Agrárias. Universidade Federal de Uberlândia. Boletim Técnico 2.

Lima, M.L., Pozza, E.A., Pozza, A.A.A., Fonseca, T.A.P.S., Carvalho, J.G., 2010. Quantificação da ferrugem asiática e aspectos nutricionais de soja suprida com silício em solução nutritiva. Summa phytopathologica, 36(1), 51-56.

Ma, J.F., Miyake, Y., Takahashi, E., 2001. Silicon as a beneficial element for crop plant. Silicon in agriculture. New York: Elsevier Science, 1, 17-39.

Moreira, A.R., Fagan, E.B., Martins, K.V., Souza, C.H.E., 2010. Resposta da cultura de soja a aplicação de silício foliar. Bioscience Journal, 26(3), 413-423.

Navarro Junior, H.M., Costa, J.A., 2002. Contribuição relativa dos componentes do rendimento para produção de grãos em soja. Pesquisa Agropecuária Brasileira, 37(3), 269-274.

Pereira Júnior, P., Rezende, P.M., Malfitano, S.C., Lima, R.K., Orrêa, L.V.T., 2010. Efeito de doses de silício sobre a produtividade e características agronômicas da soja [Glycine $\max ($ L.) Merrill]. Ciência e Agrotecnologia, 34(4), 908-913.

Philippsen, D.R., Simonetti, A.P.M.M., 2010. Efeito de aplicação de diferentes doses de silício aplicado via foliar na cultura da soja. Cultivando o saber, 3(3), 40-47. 
Reis, T.H.P., Figueiredo, F.C., Guimarães, P.T.G, Botrel, P.P., Rodrigues, C., 2008. Efeito da associação silício líquido solúvel com fungicida no controle fitossanitário do cafeeiro. Coffee Science, 3(1), 78-80.

Reis, T.H.P., Guimarães, P.T.G., Figueiredo, F.C., Pozza, A.A.A., Nogueira, F.D., Rodrigues, C.R., 2007. O silício na nutrição e defesa de plantas. Boletim técnico, 82. Belo Horizonte: EPAMIG, 1(1), 124.

Santos, H.G., Jacomine, P.K.T., Anjos, L.H.C., Oliveira, V.A., Lumbreras, J.F., Coelho, M.R., Almeida, J.A., Cunha, A.T.J.F., Oliveira, J.B., 2013. Sistema brasileiro de classificação de solos, terceira ed. Brasília-DF: Embrapa.
Sousa, J.V., Rodrigues, C.R., Luz, J.M.Q., Carvalho, P.C., Rodrigues, T.M., Brito, C.H., 2010. Silicato de potássio via foliar no milho: fotossíntese, crescimento e produtividade. Bioscience Journal, 26(4), 502-513.

Taiz, L., Zeiger, E., 2013. Fisiologia vegetal, quinta ed. Porto Alegre: ArtMed.

USDA - United States Department of Agriculture, 2018. Production, Supply and Distribuiton Online. http://www.usda.gov (acessado 19 de março de 2018).

Zago, A.S., Silva, C.A.T., Silva, T.R.B., Viecelli, C.A., Verona, E., Nolla, A., 2010. Efeito de doses de silício no desenvolvimento de soja. Cultivando o Saber, 3(2), 16-22. 